\title{
A High Electrical Field Effect to Ultrafine Particle Filter Performance on Motor Vehicle Exhaust
}

\author{
Octora Achbrinia Puspitasari, Arinto Yudi Ponco Wardoyo, Hari Arief Dharmawan, Muhammad \\ Nurhuda, Arif Budianto, Alma Shafia, Moch Agung Putra Nurwahyudi
}

\begin{abstract}
In this study, a high electric field generated by direct current was applied to an electrode filter on the motor vehicle exhaust to reduce the ultrafine particle emission. A standard motor vehicle engine in an idle condition with the engine rotation of $1000 \mathrm{rpm}$ was used as the particle source. The aluminum plates with a thickness of $0.15 \mathrm{~mm}$ were used as the positive and negative electrodes. They were placed onto an acrylic filter frame and installed on the exhaust. A signal generator producing a high stable voltage (direct current) was applied on the electrodes to produce an electric field. The influence of the applied electrical field on the filter to reduce ultrafine particles was investigated by the reduction of the concentration before and after passing through the filter. The particle concentration was measured using a TSI P-Trak 8525. The experiment result shows that applying a high electrical field on the filter affects to reduce the ultrafine particle concentration with an efficiency of $5 \%$ to $47 \%$.
\end{abstract}

Keywords: Efficiency; filtration system; motor vehicle emission; ultrafine particle.

\section{INTRODUCTION}

$\mathbf{P}_{\mathrm{M}}$ (particulate matter) emission becomes a serious concern in developing regions because of the population activity and industrialization growth. This kind of emission is also derived from the transportation sector, as the side impact of the population and motor vehicle usage growth. Generally, particulate matters originate from different sources as the primary and secondary emission. According to the size distribution of particulate matter can be classified into $\mathrm{PM}_{0.1}, \mathrm{PM}_{1.0}, \mathrm{PM}_{2.5}$, and $\mathrm{PM}_{10}$ which are the particulate matter with the diameter less than $0.1 \mu \mathrm{m}$ or is called as ultrafine particles [1], $1.0 \mu \mathrm{m}, 2.5 \mu \mathrm{m}$, and $10 \mu \mathrm{m}$ respectively $[2,3]$.

Revised Manuscript Received on January 10, 2020

* Correspondence Author

Octora A. Puspitasari, Physics Department, Brawijaya University, Jl. Veteran, Malang, East Java, Indonesia. Email: octoraniaa@gmail.com

Arinto Y. P. Wardoyo*, Physics Department, Brawijaya University, Jl. Veteran, Malang, East Java, Indonesia. Email: a.wardoyo@ub.ac.id

Hari A. Dharmawan, Physics Department, Brawijaya University, J1 Veteran, Malang, East Java, Indonesia. Email: hari_arief@ub.ac.id

Muhammad Nurhuda, Physics Department, Brawijaya University, Jl. Veteran, Malang, East Java, Indonesia. Email: mnurhuda@ub.ac.id

Arif Budianto, Physics Department, Brawijaya University, Jl. Veteran, Malang, East Java, Indonesia. Email: arif.fio@student.ub.ac.id

Alma Shafia, Physics Department, Brawijaya University, Jl. Veteran, Malang, East Java, Indonesia. Email: almashafia@student.ub.ac.id

Moch A. P. Nurwahyudi, Physics Department, Brawijaya University, J1. Veteran, Malang, East Java, Indonesia. Email: agungputra@student.ub.ac.ic
The main reason for concerning particulate matters is due to the toxicity property in human health adverse. Particulate matters are mostly known as carcinogen matters and are well-known to have a strong correlation with the physical damages (deformation) of the alveolar and red blood cells, as described in the previous study [4,5]. Especially for ultrafine particles, they have more health impacts because of the deposition ability in the organ system. After the inhalation, they deposit in the respiratory area and pass through the blood transport system, translocating to blood, heart, liver, and kidney [6,7].

As a consequent, there are many guidelines established to limit the average daily or yearly exposure to particulate matter. Another effort is by conducting a reduction, capture, filtration, or removal methods of particulate matter, such as porosity-based particulate filter [8], nanofibrous membranes [3], and many others. The previous study has been conducted to focus on the additive for fuel to decrease particulate matter emission chemically, using glycerol triacetate [9]. Each additive certainly has its own characteristics, where the chemical composition of the catalyst will also affect the level of performance stability [10].

Electrostatic-based particulate matter-filtration technology has attracted interest due to its simplicity and stability. The electrostatic principle also has a good dust-holding capacity and low-pressure drop [11]. Meanwhile, this kind of method is not commonly applied in a motor vehicle exhaust system for both the original manufacturer and the general market. Thus, there is an urgent need to decrease the particulate matter concentration emitted by motor vehicle using simple and durable technology, but having a good filtration performance of particulate matter. Therefore, it is inevitable to develop a particulate matter filtration system of a high voltage electrostatic-based filter in a motor vehicle exhaust system.

\section{MATERIALS AND METHODS}

\section{A. Ultrafine Particle Source}

A standard motor vehicle engine was used as the ultrafine particle source. It was in a good performance. The flow rate of the output emission for the filter performance was measured in the range of 1.01 to $1.10 \mathrm{~m} / \mathrm{s}$ in the idle state (1000 rotations per minute). The engine was operated 


\section{A High Electrical Field Effect to Ultrafine Particle Filter Performance on Motor Vehicle Exhaust}

using gasoline with an octane number of 90 .

\section{B. Electric Field Generation}

A signal conditioner circuit was designed to convert 12.60 Volt direct current voltage from motorcycle accumulator to 424 Volt (maximum) (Fig. 1a-b). This circuit had an inverter circuit that was used to change the input signal to 220 Volt alternate current voltage in order to have a stable positive voltage. After that, the upper amplitude was converted to a direct current using a bridge rectifier with 10 A of maximum current. The output signal was filtered using an electrolytic capacitor and divided into four variations to generate different electric fields $E_{1}, E_{2}, E_{3}$, and $E_{4}$.
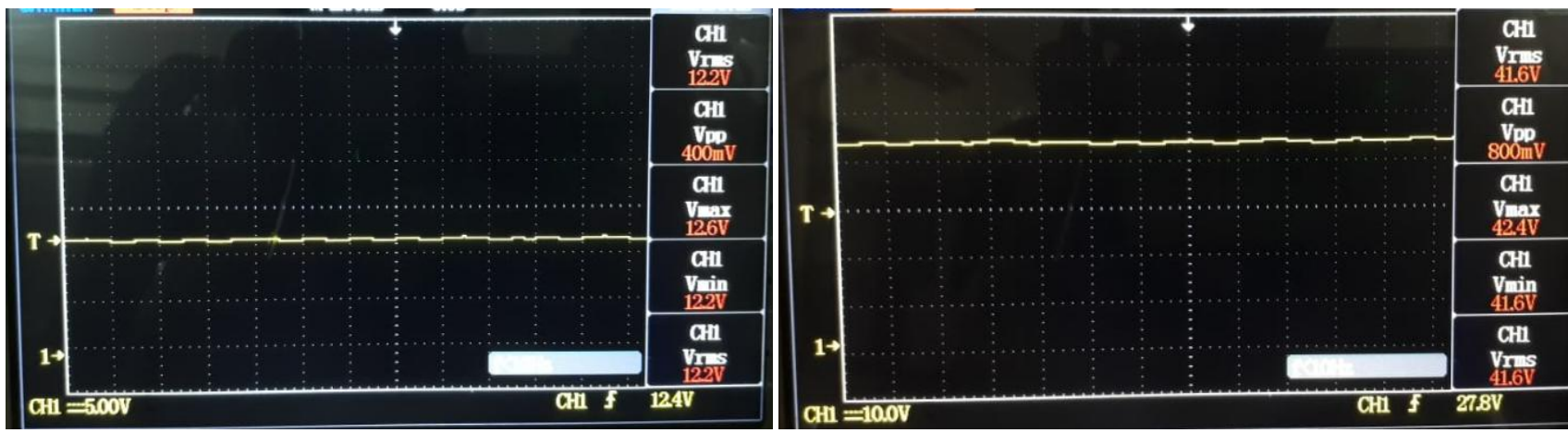

Fig. 1. A signal conditioner circuit for the aluminum electrodes to generate high electric field: (a) input, and (b) maximum output voltage signals

\section{Filter Fabrication}

The filtration system had aluminum plates with a thickness of $0.15 \mathrm{~mm}$ for the positive and negative electrodes (anode and cathode probes). The dimension of the plates was $27 \mathrm{~mm} \times 50 \mathrm{~mm}$, and the gap between each plate $(d)$ is 0.6 $\mathrm{mm}$. They were installed on the acrylic frame (thickness: 3.1 $\mathrm{mm}$ ). This filter frame was covered by a glass wool, insulator coating, and polyvinyl chloride (PVC) pipe with a diameter of $58 \mathrm{~mm}$. After that, the positive probes were connected to the positive voltage, while the negative ones were connected to the negative voltage.

\section{Filter Performance}

The filter efficiency or performance was defined as the ability of the filter in reducing ultrafine particle concentration shown by a ratio of the different particle concentrations before and after passing through the filter. The concentrations of ultrafine particles before $\left(C_{0}\right)$ and after $\left(C_{t}\right)$ applying the filter were measured under laboratory conditions using a P-Trak Ultrafine Particle Counter (TSI, Model 8525), as described in other previous study [11]. The measurement was conducted for an hour with an interval time of ten minutes per sampling time. This measurement was repeated for all-electric field variations $(n=3)$ (Fig. 2). The flow rate of the particle motion, including the temperature, were measured using an Anemomaster (Kanomax, Model A031). The filter efficiency (Ef), was shown as the percentage ratio between the concentration changes and the concentration before applying the filter, as seen in (1) below [12].

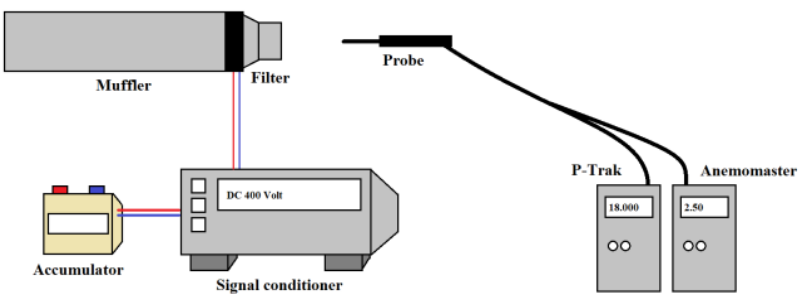

Fig. 2. Ultrafine particle measurement

$$
E f=\left[\left(C_{0}-C_{t}\right) / C_{0}\right] \times 100 \%
$$

\section{E. Statistical Analysis}

All results were presented as the mean + SEM (standard error of measurement). The correlation between electric field and filter performance was approximated using a linear function regression, in which $R^{2}>0.90$ was considered to be significantly correlated $[4,5]$. All statistical methods were performed using Microsoft Excel 2016 software.

\section{RESULTS AND DISCUSSION}

\section{A. Ultrafine Particles}

According to the experiment, there is a significant difference between the ultrafine particle concentrations before and after using filters. As seen in Table $1, E_{0}$, as the concentrations before applying the filter, are higher the concentrations obtained after using filters. For all measurement times, $E_{4}$ has the least concentration, with the range of 6,900 to 9,300 particles $/ \mathrm{cm}^{3}$. The ultrafine particle concentration decreases linearly to the period of the measurement time. This decreasing trend is obtained for all methods, whether using or without using the filter.

\section{B. Filter Performance}

The average filter's performance is presented in Fig. 3. It is clearly seen that 
peak performance occurs in the highest electric field $\left(E_{4}\right)$, $47 \% . E_{3}$ generates a lower efficiency $(26 \%)$ compared to $E_{4}$. The lowest electric field, $E_{l}$, has only $5-12 \%$ of filter performance, $1-4 \%$ lower than $E_{2}(6-16 \%)$. With a constant gap $(d)$, it indicates that the filter performance $E f$ only depends on the electric field $E$. Hence, the performance pattern of ultrafine particle reduction is estimated using linear regression. According to the statistical analysis, the value of $R^{2}$ is more than 0.80 . It means that there is a positive linear correlation between the electric field and filter performance.

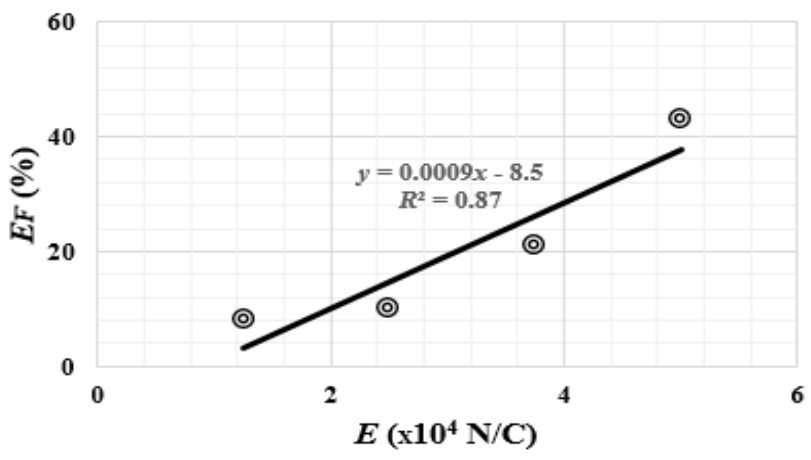

\section{Fig. 3. Correlation between the electric field of the} electrode plates and efficiency $\left(R^{2}>0.85\right)$

The ultrafine particle concentration decreases linearly to the period of the measurement time. This decreasing trend is obtained for all methods, whether using or without using filter. Applying the filter with a certain electric field reduces ultrafine particle concentration, while a larger applied voltage causes a lesser concentration. The trendline of concentration reduction shows the similarity when the filter is applied for the different electric fields. A higher electric field generates a lower concentration. The existence of an electric charge in a space with a certain radius may generate an electric related to Columb force, $F[13]$. Thus, this kind of force may influence filter performance in terms of its efficiency in reducing ultrafine particle concentration. Meanwhile, particulate matters consist electrical charges or ions, such as anions [14]. The negative ions are attached to the positive plate or anode, and the positive ions are fastened to the negative site or chatode. This cause the reduction of the particles passing through the filter.

According to Fig. 3, the efficiency is proportional to the applied electric field. Furthermore, these electrodes were attached to the voltage source, and they were charged to be positive and negative charges, respectively. The negative ions of ultrafine particles are attached to the cathode, while the negative ones come to the positive plate (anode). It will reduce the particles passing through the filter.

The flow of ionic currents between the releasing and the collecting electrodes is formed by a strong electric field. To accumulate charge by particles, several factors will be taken into accounts such as particle size, dielectric constant, and residence time in an ESP (electrostatic precipitator) [1].
Diffusion charging and field charging are the types of charging mechanisms [15]. The Brownian equation was used to calculate the motion of particles. The ions may collide when the suspended particle between the electrodes is filled. These phenomena are called diffusion charging. The diffusion can be estimated based the equation as below [15]:

$$
q(t)=\frac{d_{p} k T l}{2 \theta} \ln \left(1+\left(\frac{\pi d_{p} \overline{c_{t}} C_{t} e^{2} t}{2 k T}\right)\right)
$$

where $q(t)$ is a charge of a particle (Coulomb) at a time, $t, d_{p}$ is particle diameter, $k$ is Boltzmann constant, $e$ electron charge equals $1.6 \times 10^{-19} \mathrm{C}, T$ is absolute temperature, $C$ is thermal velocity, and $C_{t}$ is a number of particle concentration. We can estimate the number of charged particles by using this equation. The ability of the plates to attach the particles depending on the applied voltages. The ability is presented as the electrostatic force related to the voltage using (3) and (4),

$$
\begin{gathered}
V=\frac{E_{P}}{q} \\
E=k \frac{q^{2}}{r^{2}}=\frac{E}{q}
\end{gathered}
$$

where $V$ is the electrical potential, $E$ is the electrical field, $K$ is Coulomb constant, $r$ is the distance, $F$ is the electrostatic force, $E_{p}$ is potential energy, and $q$ is the electrical charge. Based on this equation, we can find that higher voltage will generate a higher electric field. The higher electric field will produce high electrostatic force. The larger electric field causes lower particle concentration. We assume that particles with higher diameter have higher potential to collide when the particles fill the gap of the filter. Large particles are potentially impacted by an electric field [15].

The emission temperature does not affect efficiency. Because the temperature is relatively constant when we applied the filter and without filter on the exhaust. According to the previous study, emission temperature does not affect the reduction of the particles. The ambient temperature and humidity temperature kept constant during the filter test.

\section{CONCLUSION}

The effect of the high electrical field of the electrostatic filter on reducing ultrafine particles has been investigated The result shows that the high electric field applied to the electrostatic filter effects to the reducing of ultrafine particle concentration. A higher electrical field applied to the motorcycle exhaust filter causes more reduction of ultrafine particle concentration. The applied electrical field is obtained proportionally to ultrafine particle concentration reduction. 


\section{A High Electrical Field Effect to Ultrafine Particle Filter Performance on Motor Vehicle Exhaust}

Table- I: Ultrafine particle concentrations before and after applying the filter in a time series (particles/cm $\left.\mathrm{cm}^{3}\right)$

\begin{tabular}{|c|c|c|c|c|c|}
\hline \multirow{2}{*}{ Time (minute) } & \multicolumn{5}{|c|}{ Ultrafine particles (particles $/ \mathrm{cm}^{3}$ ) } \\
\hline & $E_{0}$ & $E_{1}$ & $E_{2}$ & $E_{3}$ & $E_{4}$ \\
\hline 10 & $14,500 \pm 115$ & $13,800 \pm 290$ & $13,500 \pm 296$ & $12,300 \pm 885$ & $9,300 \pm 130$ \\
\hline 20 & $13,300 \pm 303$ & $12,500 \pm 390$ & $12,300 \pm 396$ & $10,900 \pm 949$ & $7,800 \pm 160$ \\
\hline 30 & $13,200 \pm 172$ & $12,300 \pm 110$ & $11,800 \pm 105$ & $10,200 \pm 986$ & $7,100 \pm 210$ \\
\hline 40 & $13,000 \pm 182$ & $12,000 \pm 283$ & $11,600 \pm 283$ & $10,000 \pm 827$ & $6,900 \pm 140$ \\
\hline 50 & $13,700 \pm 160$ & $12,000 \pm 263$ & $11,500 \pm 263$ & $10,100 \pm 284$ & $7,300 \pm 140$ \\
\hline 60 & $12,800 \pm 165$ & $11,500 \pm 148$ & $11,300 \pm 148$ & $10,100 \pm 576$ & $7,500 \pm 180$ \\
\hline
\end{tabular}

\section{ACKNOWLEDGEMENTS}

All authors wish to acknowledge the role of LPPM (Institute of Research and Community Services) of Brawijaya University, Malang, Indonesia, for the financial support provided (contract number: 330.12/UN10.C10/PN/2019). The team also acknowledge Eko Teguh P. A., Hamid Syaifullah, Lisa Andreini, Sasa Vio Anggreani, and all members of the Laboratory of Air Quality and Astro Imaging, Physics Department, Brawijaya University, for the efforts during the experiment.

\section{REFERENCES}

1. W. Kim, J. Hee, H. Kim, Y. Jin, and S. Soo, "Effect of temperature on carbon nanoparticle collection efficiency using photoelectric ESP," Sci. Total Environ., vol. 407, pp. 2136-2141.

2. H.J. Kim, S.J. Park, D.I. Kim, S. Lee, O.S. Kwon, and I.K. Kim, "Moisture Effect on Particulate Matter Filtration Performance using Electro-Spun Nanofibers including Density Functional Theory Analysis," Sci. Rep., vol. 9, 2019, pp. 1-8.

3. X. Zhao, S. Wang, X. Yin, J. Yu, and B. Ding, "Slip-Effect Functional Air Filter for Efficient Purification of $\mathrm{PM}_{2.5}$," Sci. Rep., vol. 6, 2016, pp. 1-11.

4. A.Y.P. Wardoyo, U.P. Juswono, and J.A.E. Noor, "Comparison of lung damages due to petrol and diesel car smoke exposures: histological study," Int. J. GEOMATE, vol. 15, 2018, pp. 124-129.

5. A.Y.P. Wardoyo, U.P.Juswono, and J.A.E. Noor, "How exposure to ultrafine and fine particles of car smoke can alter erythrocyte forms of male mice," Polish J. Environ. Stud., vol. 28, 2019, pp. 2901-2910.

6. A. Nemmar, B. Vanquickenborne, D. Dinsdale, M. Thomeer, H. Hoylaerts, H. Vanbilloen, L. Montelmans, and B. Nemery, "Passage of inhaled particles into the blood circulation in humans," Circulation, vol. 105, 2002, pp. 411-414.

7. M. Semmler, J. Seitz, F. Erbe, P. Mayer, J. Heyder, G. Oberdörster, and W.G. Kreyling, "Long-term clearance kinetics of inhaled ultrafine insoluble iridium particles from the rat lung, including transient translocation into secondary organs," Inhal. Toxicol., vol. 16, 2004, pp. 453-459.

8. U. Hajar, A.Y.P. Wardoyo, and Masruroh, "Developing and characterization of an ultrafine filter made of banana leaf and water hyacinth to reduce motorcycle emission," Appl. Ecol. Environ. Res., vol. 17, 2019, pp. 1959-1965.

9. E. Akbarian and B. Naja, "A novel fuel containing glycerol triacetate additive, biodiesel and diesel blends to improve dual-fuelled diesel engines performance and exhaust emissions," vol. 236, 2019, pp. 666-676.

10. Y. Gao, F. Meng, Y. Cheng, and Z. Li, "General Influence of fuel additives in the urea-nitrates solution combustion synthesis of $\mathrm{Ni}-\mathrm{Al} 2 \mathrm{O} 3$ catalyst for slurry phase CO methanation," Applied Catal. A, Gen, vol. 534, 2017, pp. $12-21$.

11. A.Y.P. Wardoyo, A. Budianto, and Abdurrouf, "Filtration of submicron particles from motorcycle emission using a DC low electrostatic filter," Int. J. Appl. Eng. Res., vol. 12, 2017, pp.1725-1728.

12. B. Yang, Y. Shen, Y. Su, P. Li, Y. Zeng, S. Shen, and S. Zhu, "Removal characteristics of nitrogen oxides and particulates of a novel Mn-Ce-Nb-Ox/P84 catalytic filter applied for cement kiln," J. Ind. Eng. Chem., vol. 50, 2017, pp. 133-141.

13. N. Wakatsuki and A. Yamamoto, "Bouncing of a Reed Switch due to Coulomb's Electrostatic Force”, 2006, pp. 165-169.

14. R.J.C. Brown and P.R. Edwards, P.R., "Measurement of anions in ambient particulate matter by ion chromatography: A novel sample preparation technique and development of a generic uncertainty budget," Talanta, vol. 80, 2009, pp. 1020-1024

15. A. Sudrajad and A.F. Yusof, "Review of Electrostatic Precipitator Device

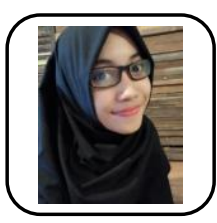
for Reduce of Diesel Engine Particulate Matter,' Energy Procedia, vol. 68, 2015, pp. 370-380.

\section{AUTHORS PROFILE}

Octora Achbrinia Puspitasari, is the first author of

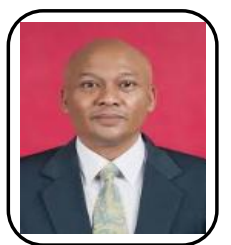
this paper. She is doing her final task project in Laboratory of Air Quality and Astro Imaging, Physics Department, University of Brawijaya, together with Arif Budianto.

Arinto Y.P. Wardoyo, is a lecturer in Physics Department, Brawijaya University. He is the leader of Laboratory of Air Quality and Astro Imaging, Physics Department, University of Brawijaya. His expertice is air quality study, environmental health and impact, and filter development.

Hari Arief Dharmawan, is a lecturer in Physics Department, Brawijaya University. He is the leader of Laboratory of Air Quality and Astro Imaging, Physics Department, University of Brawijaya. His expertice is instrumentation and embedded system.

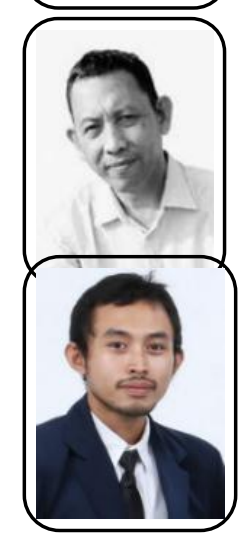

Muhammad Nurhuda, is a lecturer in Physics Department, Brawijaya University. He is the leader of Laboratory of Air Quality and Astro Imaging, Physics Department, University of Brawijaya. His expertice is energy development.

Arif Budianto, is a doctoral student in Physics Department, Brawijaya University. He has a final task project in Laboratory of Air Quality and Astro Imaging, Physics Department, University of Brawijaya, together with Prof. Arinto Y.P. Wardoyo, as his lecturer.

Alma Shafia, is a bachelor student of Physics Department, Brawijaya University. She has a final task project in Laboratory of Air Quality and Astro Imaging, Physics Department, University of Brawijaya, together with Prof. Arinto Y.P. Wardoyo, as her lecturer.

Moch Agung Putra Nurwahyudi is having a final task research about electrostatic filter. He is a student of Physics Department, Brawijaya University. He has a final task project in Laboratory of Air Quality and Astro Imaging, Physics Department, University of Brawijaya.

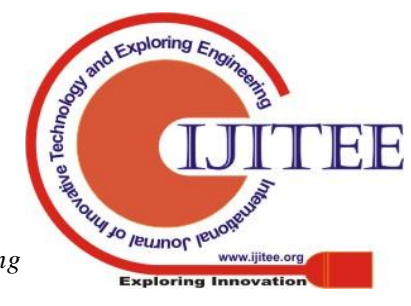

